\section{Deidre Geduld}

(deidre.geduld2@nmmu.ac.za)

Heloise Sathorar

(Heloise.Sathorar@nmmu. ac.za)

DOI: http://dx.doi. org/10.18820/2519593X/pie. v34i1.4

ISSN 0258-2236

eISSN 2519-593X

Perspectives in Education

2016 34(1): 40-52

(c) UVIUFS

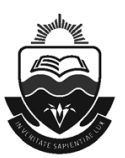

Humanising pedagogy:

An alternative approach

to curriculum design that

enhances rigour in a B.Ed.

programme

\begin{abstract}
The minimum requirements for teacher education qualifications (MRTEQ) draws attention to the complexity of teaching as an activity that is premised upon the acquisition, integration and application of different types of knowledge practices or learning. As such, all initial teacher education programmes in South Africa should be designed such that they include disciplinary knowledge, pedagogical knowledge, practical knowledge, fundamental knowledge and situational knowledge. These types of knowledge underpin a teacher's ability to facilitate meaningful learning in the classroom, which in turn facilitates higher education's responsiveness to societal needs.

In this article, we reflect on the faculty's recent curriculum renewal journey towards designing a coherent and rigorous B.Ed. programme. We locate our curriculum renewal journey in critical theory and our new curriculum itself is grounded in humanising pedagogies, critical reflection and inquiry. We also describe the consultation and collaborative processes we engaged in to ensure that our new B.Ed. programme would be responsive to the needs of our students and society.
\end{abstract}

Keywords: Curriculum renewal, education theory, humanising curriculum framework, academic rigour, curriculum responsiveness

\section{Introduction and background}

This paper is premised on the understanding that teaching is a compound activity. Thus, teacher education programmes need to be designed in such a manner that students are able to acquire, integrate and apply a range of knowledge types, such as disciplinary knowledge, pedagogical knowledge, practical knowledge, fundamental knowledge and situational knowledge (Department of Higher Education and Training, 2015). These various types of knowledge's of learning underpin teachers' ability to make meaningful connections with the practice of education to facilitate meaningful learning. Teacher education programmes should be designed to enable the student to acquire and apply these knowledge's in an integrated, fused manner. 
This article describes our recent curriculum renewal journey towards designing a coherent and rigorous B.Ed. programme. In order to understand the complexities of our journey, it is firstly important to share our faculty's evolving identity, coloured by diverse ideologies and biographies that shape current ways of being as teacher educators at a transforming postapartheid, post-merger higher education institution in South Africa.

The current NMMU Faculty of Education came into being in 2005 as a result of the amalgamation of three former higher education institutions in the Nelson Mandela Metropole: The University of Port Elizabeth (UPE), the Port Elizabeth Technikon, and the PE campus of Vista University. UPE, a former white institution, was established during the apartheid years and operated as an Afrikaner Broederbond stronghold. The university promoted the political ideology of the National Party, upheld the principles of Christian National Education (CNE) and rooted its education in the philosophy of fundamental pedagogics. PE Technikon focussed predominantly on technically oriented undergraduate diplomas and to a lesser extent, postgraduate qualifications. The primary focus was on preparing students for industry. Countrywide, Vista University's multi-campuses were established to accommodate black students who could not, due to policy, access so-called white universities. As such, the Vista PE campus was located at Missionvale, a black township on the outskirts of Port Elizabeth. Although all three institutions offered teacher education programmes, there was little overlap in terms of the content and structure of modules. Hence, during the merger process programmes were, in most cases, retained.

A large component of our current staff attended school and university during the apartheid era when the vast majority of state-funded HEls and teacher training colleges were merely complying with the status quo. Furthermore, for many colleagues, the conception of 'curriculum' during the time of the merger was still rooted in a modernist paradigm, understood according to Tyler's cause-and-effect, prediction-and-control model (Cullen \& Hill, 2013). In addition, the vast majority of staff, black and white, went "through the mill of fundamental pedagogics" (Morrow, 2007: 135), our educational philosophies grounded in positivist certainty and rationality, with reality assumed to be stable and predictable (Cullen \& Hill, 2013). Fundamental pedagogics propagated inter alia the idea that the child is a non-adult en route to adulthood. In order to ensure a meaningful being en route to, and a gradual conquest of adulthood, the assistance and support of a "proper adult", was seen as indispensable (Landman et al., 1982: 3). Since fundamental pedagogics adopted Christianity as the 'only' philosophy of life, forms of '-isms', such as pragmatism, liberalism, Marxism, existentialism and humanism were seen as undermining Christianity and as such were rejected. Paulo Freire's Pedagogy of the Oppressed (1970) and other progressive educational texts were banned for promoting 'liberal, communist' ideology. In general, educational discourse at most statecontrolled education institutions during these years disregarded the impact of poverty, racism, and cultural struggles on the education of the majority of South African children, producing an "epistemological veil" (Apple, 2011: 223).

In order to transform the faculty, renew its curricula and facilitate much-needed educational change, thoughtful engagement with profound transformation was necessary. This would imply reconfiguring our inner personal landscapes as teacher educators. We had to revisit and interrogate our individual ideologies, philosophies, epistemologies, pedagogies and ontologies in a post-colonial, post-apartheid, post-merger faculty. Ultimately, we had to redefine who we are, not only as individuals but also as a collective. 


\section{A curriculum underpinned by critical theory}

Critical theory encapsulates multiple strands of scholarship united by a deep commitment to human emancipation. It was initiated by a group of prominent interdisciplinary thinkers whose 'members' include Max Horkheimer, Theodor Adorno, Herbert Marcuse, Eric Fromm and Jurgen Habermas. The interests of these intellectuals soon broadened into an attempt to build a theory of critical action dedicated to guiding a political, economic and intellectual revolution. According to these theorists, a "critical" theory may be set apart from a "traditional" theory according to a specific practical purpose: a theory is critical to the extent that it seeks human "emancipation from slavery", acts as a "liberating ... influence" and works "to create a world which satisfies the needs and powers" of human beings (Horkheimer, 1972: 246). Since such theories aim to explain and transform all the circumstances that enslave human beings, many "critical theories" in the broader sense have been developed. The result is to be an eventual democratic and free society founded on concepts such as social justice, interpersonal respect, universal rights and global citizenship.

Higher education within South Africa needs to prepare teachers and scholars to confront the current political climate within the country. We need to change our theoretical orientation to one that is adaptable, critical and radical in the current South Africa. However, Arum and Roksa (2011) are of the opinion that the curriculum structures at universities do not indicate measurable improvement in critical thinking ability within students. One of the purposes of teacher education is to assist in improving the quality of teaching in schools and thus, student teachers need to learn more than the technicalities of teaching as well as something beyond classroom management techniques. As an alternative, Beyer (2001) suggests that teacher preparation courses include experiences that incorporate theoretical understandings, conceptual analyses, a range of inquiry orientations and activities, an array of literatures and research studies and an openness to novel ways of seeing and thinking about teaching, schooling and society. Teacher educators need to prepare student teachers for life after the classroom but also to help them to be able to change the world (De Leon \& Ross, 2010).

A curriculum located within critical pedagogy focuses on student experience and social action, thus focusing on social dimensions and consequences of educational practices, the ideological meaning of texts and experiencing the power relations in schools and the need to interrogate theory and practice in new ways. Cohen's (1999) strategies for dealing with controversial issues include inquiry, dialogue and multiple perspectives as the focus as well as community-based learning and bringing the world into the classroom.

Through a critical interrogation of relationships and emerging identities in pedagogical contexts, we argue that three dominant patterns of interaction and experience shape our teacher education pedagogies:

- cultural dimensions of self - ways of being;

- intellectual dimensions of self - ways of knowing;

- social dimensions of self - ways of interacting with others.

Surrounded by these dominant patterns, the emerging humanness becomes realised through and in relation to historical, cultural and social dynamics at play in the experiences of individuals, groups and institutions. We envisage the growth of the whole person (not a facet of a person) in relations with others. Viewing our curriculum through a lens of humanising 
pedagogy helps us to understand that teacher education is a process and a vision for life in schools, institutions, society and beyond.

\section{Our journey towards a humanising curriculum framework underpinned by critical theory}

After an intense revisioning journey, the faculty embarked on a comprehensive and intensive process of curriculum renewal, firstly defining its 'groundation". This part of the renewal process was characterised by critical reflective inquiry and inclusive and participatory conversations, drawing on voices across a wide spectrum of stakeholders including students, alumni, teachers, principals and community leaders. These engagements enabled us to develop a shared understanding of our humanising philosophy of teacher education. In order for student teachers to be humanised, the teacher educators too must be humanised. In Freire's (1970) view, dehumanisation is reciprocal and existential. If a teacher dehumanises students, then the teacher too is dehumanised.

The 'groundation epoch' was a critical episode in our journey as it forced us to revisit individual teaching philosophies, pedagogies and identities, shaped by diverse histories and biographies and redefine these. More engagements followed in the form of critical reflective inquiries and conversations. Inputs from these sources as well as more intensive discussions, debates, creative workshops and consultations, enabled us to develop a curriculum framework cradled in our vision, mission and pedagogy.

Pedagogy can be understood to constitute a set of social and political relations that "connects the apparently self-contained act of teaching with culture, structure and the mechanisms of social control" (Alexander, 2008: 3). As Bernstein (1999: 148) further observes, "pedagogy is a sustained process whereby somebody acquires a new form or develops existing forms of conduct, knowledge, practice and criteria from somebody or something deemed to be an appropriate provider and evaluator". We employed Tintiangco-Cubales, Kiang and Museus's (2010) definition of pedagogy to guide our curriculum framework (see diagram below): Pedagogy is seen as a philosophy of education informed by positionalities, ideologies and standpoints (of teacher and learner). It takes into account the critical relationships between the purpose of education, the context of education, the content of what is being taught and the methods of how it is taught. It also includes (the identity of) who is being taught, who is teaching, their relationship to each other and their relationship to structure and power (Tintiangco-Cubales et al., 2010).

Power relations also mark the scope and content of higher education curricula. This is best reflected in the contested field of education policy making. Take, for example, the combined efforts of South African senior government officials, media experts, policy makers and academics to classify and legitimatise what types of knowledge and scientific practices and discourses should be taught and in some circumstances made compulsory through institutions. It is an ideological battlefield. Far from being neutral, random or even unbiased, the content and design of HE curricula is shaped by the cultural and political sensibilities of a given society (Korthagen, 2002). More importantly, national prescriptions for education policy

1 With recognition to the late Andrew Sauls, in life a renowned poet from (The Northern Areas of Port Elizabeth) and SGB member of one of the local schools. 
implementation and development are governed and sometimes impeded by transnational trends including the needs of labour markets and the global economy.

This point of departure that often divorces context from the discussion around training teachers manages to do a few things. It attempts to separate education from politics, it positions the institution (and by association the content and pedagogy within it) as 'neutral' thus shifting any critique and 'blame' to the context (the teachers, the communities and the students) and this in turn removes any responsibility in creating alternative solutions from the academy. Simultaneously, we are dealing with the ramifications of the current global debate around educational reform that align educational goals to those of the labour market. Schooling in post-apartheid South Africa is increasingly linked to employability, economic growth; the needs of business and ensuring our children have the 'correct' skills (for the market). This narrow view of the purpose of education redefines essential elements of learning and teaching in ways that standardise, quantify and limit our understandings of competence and performance.

Our 'old' curriculum had minimal input from teachers, was developed by 'experts' and publishers and was pre-packaged and "designed to be applied to any classroom context regardless of the historical, cultural, and socioeconomic differences that characterise various schools and students" (Giroux, 2009: 442). Giroux (2009) points out that the de-skilling of teachers appears to accompany the adoption of management-type pedagogies. This management type paradigm seeks to 'improve' education by "teacher-proofing" it and teachers are then relegated to semi-skilled, low-paid workers in the mass production of education (Giroux, 2009: 442). Despite insistence from all corners for the need to develop critical thinkers, solid literacy and numeracy skills and students that are able to contribute meaningfully to the development of the country, the current structure and culture of our education system is still highly prescriptive, standardised and driven towards narrow and specific assessment that favours rote learning, memorisation, standardisation and a culture of conformity.

As part of our faculty's agenda for the institution to take an active role in preparing teachers for schools, our humanising curriculum framework offers the reconnection of education to social justice - equity in the social, cultural, racial and economic realms - and disconnecting education from the reproduction of social and societal inequities (Furumoto, 2003). Freire (2005) offers a humanising pedagogy as an approach where the teacher is a revolutionary leader in establishing a permanent relationship of dialogue with her/his students in an effort to build confidence in students who may be alienated or feel alienated from teaching and learning. Our perspective of a humanising approach in education is grounded in critical theory, which is about coming to a critical understanding of oneself and understanding the self in relation to society (Christensen, 2000).

We sought to create a curriculum framework where student learning was validated and where the shared experience and equality of student teachers was more in evidence. We propose a humanising pedagogy, which allows student teachers to co-create opportunities and situations from which they may organise and develop solid theoretical and practical approaches. These considerations have led us towards a set of fundamental questions guiding the curriculum choices we need to make, namely, what do we choose to teach, how will we do so, where will this learning and teaching take place, and how do we know that learning has taken place? 
The following diagram captures our 'humanising curriculum framework' that guided our renewal work:

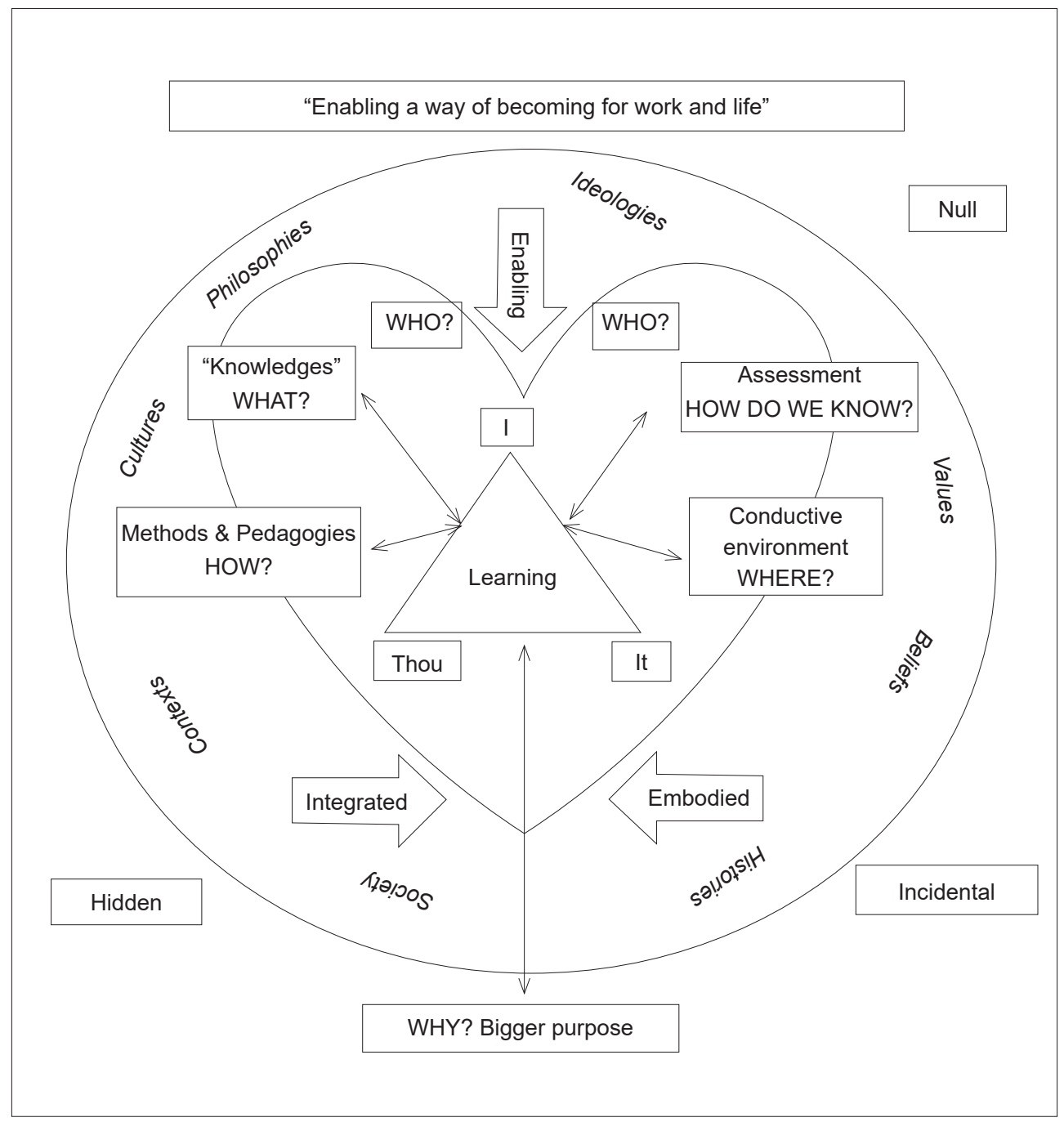

Figure 1: NMMU Faculty of Education's humanising curriculum framework

There are several layers of meaning encapsulated in this diagram. The outer layer of the circle acknowledges that our work is informed by and seeks to contribute to a range of historical, philosophical, political and cultural dimensions of our lives within a society (Zinn et al., 2014). At the centre of this diagram, is a heart representing the so-called who question, who are we as teacher-educators? Who are our students and who are their prospective learners? At the centre of the heart is the Hawkin's (1974) learning triangle symbolising the learning act. Linked to the learning triangle are the critical questions of what will be taught, how it will be taught, where it will be taught and how we know learning has taken place. All these questions are intrinsically linked to the I (teacher) - THOU (student) - IT (content) interaction on the 
learning triangle. For the purpose of this paper, the IT will specifically refer to the disciplinary knowledge of the education theory modules and the work integrated learning modules in the B.Ed. programme.

Informing these reciprocal relationships are also the understandings and philosophical orientations of our 'golden threads' of humanising pedagogies and a culture of critical reflection and inquiry (Rodgers, 2002; Dewey, 1938). Thus, there is a commitment to pedagogy that:

- Is student-focused;

- Is embedded in processes of dialogue and meaning making;

- Focuses on the praxis that combines new knowledge with meaning making through cycles of learning, action and reflection;

- Recognises the diversity of knowledge and experience of students as they enter the institution;

- Seeks to build bridges and scaffolds between this knowledge and the history of ideas, discourses and literacies of academic life;

- Consciously engages with the tension between the production of local and the global knowledge.

Hence, Freire (2005) argues that it is essential to realise that when we accept the struggle for humanisation we also accept, from that moment, our total responsibility for the struggle. We must realise that we are fighting not merely for freedom from hunger but for freedom to create and construct, to wonder and to venture.

The next section deals with humanising pedagogy within our curriculum frameworks as a way to set the backdrop for pedagogical transaction in a post-apartheid society.

\section{How our humanising curriculum framework contributes to academic rigour in the B.Ed. programme}

Academic rigour is determined not just by what is taught but how it is taught and how it is assessed (The Hechinger Report, 2008). Thus, to determine the rigour of a curriculum, questions should be asked about all three components of rigour - content, pedagogy and assessment (The Hechinger Report, 2008).

Schmidt (2008) describes a rigorous curriculum as being focused, coherent and appropriately challenging. Similarly Slonimsky and Shalem (2006: 36) refer to the appropriateness of the curriculum by investigating higher educations 'responsiveness' to the difficulties experienced by 'under prepared' students. Moll (2004) developed the notion of 'curriculum responsiveness' which he argues includes economic, cultural/institutional, disciplinary and learning responsiveness. Moll (2004 as cited by Slonimsky and Shalem, 2006: 36) briefly describes economic responsiveness of the curriculum as the extent to which the teaching and learning in a university meet the changing needs of employers of graduates. Jacobs, Snider and Willen (The Hechinger Report, 2008) support the notion of economic responsiveness in that they highlight the importance of consulting employers to establish what their expectations of graduates are and then enhance the rigour of the curriculum by ensuring that these aspects are covered by the said curriculum within context.

Furthermore, Moll (2004) refers to the cultural responsiveness of the curriculum as accommodating the diversity of socio-cultural realities of students by developing a wider variety 
of instructional strategies and learning pathways. Jacobs, Snider and Willen (The Hechinger Report, 2008) also highlight the importance of talking to students to establish their interest and context and to incorporate this into the curriculum. The disciplinary responsiveness of the curriculum refers to a curriculum's responsiveness to the nature of its underlying knowledge discipline that essentially refers to the link between the way knowledge is produced and the way students are educated and trained in the discipline area. From a teaching perspective, this requires socialisation into academic inquiry of specialised knowledge's (Moll, 2004). Jacobs, Snider and Willen (The Hechinger Report, 2008) who highlight the importance of a curriculum developing higher order critical thinking skills in students also support this notion.

Finally, Moll (2004) suggests that learning responsiveness entails teaching and assessing students in ways that are accessible to them. This means not only including students in determining what is valued about the underlying discipline in terms of assessment but also adjusting the teaching to the rhythms, tensions and emotions of learning (Slonimsky \& Shalem, 2006: 37).

To attain rigour in our B.Ed. curriculum we conceptualised our humanising curriculum framework to be responsive to the needs in higher education. Paramount in our humanising curriculum framework is "who" our students are. For this purpose, we consulted students and alumni to establish a profile of our student. This assisted us in understanding context and allowed us to accommodate students' diverse socio-cultural realities in the range of instructional strategies and learning pathways (Moll, 2004). Oliva (2009) emphasises the importance of a curriculum specifying student, societal and school needs. This is in line with the "what" element in our humanising curriculum framework where what the student needs to know is the main focus. Moll (2004) refers to this as the economic responsiveness of the curriculum. However, we acknowledge that within South Africa's two-tier education system one for the middle class and rich, predominantly English and Afrikaans speaking elite and one for the poor, African language speaking majority; we should strive to achieve transformation and equality.

We consulted with a variety of other stakeholders including school principals, mentor teachers and Department of Education officials to establish what skills are required of teacher education graduates. A range of aspects was highlighted including resilience, ability to interact with society, classroom management and administration, handling disciplinary issues and a strong content knowledge. These aspects were addressed in the module design to ensure that students are adequately prepared to address the needs described earlier. It could be argued that the economic responsiveness of a curriculum contradicts the principles of critical theory that underpinned our renewal process; however, for us it highlighted the nuances between the reality and the ideal. We thus, had to ensure a balanced approach whereby students would be encouraged to think critically and to engage in meaningful dialogue in responding to societal needs while at the same time ensuring that they are aware of the requirements of the school, the Department of Education and society.

The "how" in our humanising curriculum framework refers to the pedagogies and methods of teaching. This echoes Moll's (2004) notion of disciplinary responsiveness in the curriculum. The "where" element of our curriculum framework refers to a conducive learning environment while the "how do we know" refers to appropriate assessment that will establish whether learning took place. All three of these elements can be associated with Moll's (2004) notion of learning responsiveness. Jacobs, Snider and Willen (The Hechinger Report, 2008) also support 
the notion of the learning responsiveness of a curriculum and they encourage curriculum makers to learn the most from students and to ask why they learn more in some classes than others. Furthermore, they encouraged curriculum makers to analyse assessment activities to establish whether it meets the requirement of developing high-order critical thinking skills.

As a faculty, we engaged in a review and analysis of our current curriculum. This called for deep reflection on our own practice. In addition to this, we consulted widely with students across the three different B.Ed. programmes and over the four year span to establish in which modules they learn the most and why. We also tapped into the voice of alumni to establish which modules that they completed during their study assisted them the most during practice. The information gathered during these sessions informed the programme framework and module design conceptualisation.

\section{How our humanising curriculum framework translated into rigorous and coherent modules}

The B.Ed. foundation phase (FP), intermediate phase (IP), senior phase and further education and training phase (SP and FET) programmes at NMMU are bound by common education theory and school based learning (SBL) (or WIL) modules. In the process of curriculum renewal, it was important to ensure that the humanising curriculum framework translates into responsive modules that address the needs of students, the employers (schools/Department of Education) and society. The best place to manifest the responsiveness of the curriculum would be in the common education theory modules and the SBL modules in order to achieve coherence across programmes and integration between education theory and the SBL modules. Teacher education thus becomes a theoretically informed field where student teachers first acquire the theoretical and conceptual knowledge to put this into practice (Reeves \& Robinson, 2014: 238).

First year student teachers are required to do the Education I module - Self and Human Development. Korthagen (2002), states that development takes existing knowledge and experience as a useful platform on which to build. This module aims at allowing students to reflect on their context and histories. Furthermore, it allows the student to expose "who" they are to us the teacher educators so that we, through the cultural responsiveness of the curriculum, can accommodate their socio-cultural diversity (Moll, 2004). Furthermore, the SBL I module is closely linked to the Education I module to achieve that integration of reflection and knowledge. A diversity of school contexts through four, daylong observation visits in which the general day-to-day operations of schools could be contrasted from the perspectives of students and teachers is also incorporated. These dimensions draw on a major purpose of social justice education in which the unsettling of cherished beliefs or assumptions about the world become not only unavoidable but also necessary (Berlak, 2004).

In the SBL and other modules, students discuss their school experience visits in smallgroup discussions. Here emphasis is placed on the social construction of groups and societies and on the deconstruction, or elimination of political, economic and social oppression. The groups ought to be constructed in such a way that they promote structured dialogue. Through a dialectical process, student teachers become aware of who they are and where they come from and are able then to know reality on a higher level. The goal of critical theory, according to Popkewitz (1984: 45), is to "change the world not describe it". To engage in the dialectical 
process causes an increased awareness of reality and change occurs. Such change is not seen as serendipitous but as a dialectical process that leads to the emancipation of humankind.

The Education II module is called - The Self, Society and Education and focuses on the "what" a teacher needs to know, "how" learning takes place and "where" learning takes place. The module provides the student with an understanding of how "the self" (a teacher) interacts with society in the paradigm of education. The teacher gains an understanding of what is required of a teacher to work in a diverse society - aligning to the economic responsiveness of the curriculum. Furthermore, the student will be introduced to the cultural responsiveness of the curriculum (Moll, 2004) by studying a variety of instructional strategies to accommodate the diversity of their own learners. This knowledge enables student teachers to respond (act to address the needs) to their environment. Kaufman (1984) summarised Marx's concepts on the relation between action and knowledge: Marx's doctrine maintains that the knowing of reality was also the changing of it. That said, knowledge could not be understood independently of its relation to action. Action, within a mundane perspective, changes the objects in the environment acted upon and it changes the subject (Kaufman, 1984: 81). Marx viewed this interrelationship between knowledge and action as intrinsic to peoples' natures. Knowledge produced change in people and change impelled action.

In the third year, the education theory module focuses on the foundations of education and the theories of education. Here students engage with a variety of education theories and focus on curriculum theories. The students are exposed to the South African curriculum when they visit the schools during the SBL module where they are required to present lessons for the first time to classes under the supervision of their mentor teachers. The third year modules align themselves well with Moll's (2004) disciplinary responsiveness of the curriculum. These modules address the "what", the "how" and the "how do we know" elements of our humanising curriculum framework.

The theories that students are exposed to in these modules highlight the difference between appearance and reality and motivate action rather than directions for action. Habermas (as cited in Held, 1980: 349) explains as follows:

They cannot dictate and justify action. Theory can only be used to create agents capable of full participation in decisions concerning action and it can be used to support arguments in favor of certain courses of action. But it cannot be used, in any automatic or mechanistic way, to generate strategy or to ensure the success of strategic action

The fourth year is a culmination of the previous three years of study, as students are required to reflect on what they have learnt and experienced during their previous three years in order to develop their own teaching philosophy. The fourth year SBL module requires students to be at a school for a whole year and to form part of a community of practice where they can implement their teaching philosophy and all that they have learnt over the past three years. It allows the student to engage with diverse learners, to learn from teachers in practice, to implement the curriculum and to focus on the assessment thereof. Most of all it will allow the student to adjust their teaching to the rhythms, tensions and emotions of the learning environment.

The fourth year modules support Moll's (2004) notion of learning responsiveness of the curriculum. It attempts to help students question and challenge domination and the beliefs and practices that dominate. In other words, it is a theory and practice of helping students achieve 
critical consciousness. However, as Darling-Hammond and Ducommun (2012) note: a highquality teacher may not be able to offer high-quality instruction in a context where there is a mismatch between the demands of the situation and his or her knowledge and skills. Thus, this serves as motivation for the following suggestions to form part of a teacher education curriculum that will enable student teachers to be effective in their teaching:

- Well-supervised student teaching experiences that were also well-matched to the subjects, grade levels and students they would later teach;

- More course work in teaching subject specialisations and teaching methods;

- Focused courses helping student teachers acquire specific practices and tools that they can apply in their student teaching or practicum experiences;

- A capstone project that would usually require a performance assessment or portfolio of their work done in classrooms with learners

In evaluating our humanising curriculum framework, it is clear for us that education is humanising when it is critical, dialogical and praxical.

\section{Conclusion}

We have reflected on our recent B.Ed. curriculum renewal journey towards a coherent, rigorous programme, enabling the beginner teacher to confront the numerous challenges synonymous with South African schools. We believe that the specific nature of this journey, underpinned by a critical theory, emancipated us from previously held assumptions, thereby enabling us to design an authentic, collectively owned, rigorous new B.Ed. programme. We suggest that with the thoughtful implementation of this programme we may be able to respond to the needs of society (Slonimsky \& Shalem, 2006) by cultivating student teachers who, through on-going critical reflective inquiry, will indeed become the much needed 'transformative intellectuals', as proposed by Giroux (1988).

As these programmes are to be implemented, we acknowledge that much reflective work still needs to be done towards on-going refinement. This we will aim to do, through collaborative, collegial dialogue that reflects on problems and work towards solutions that provide the catalyst for our own and our students' learning (Henderson \& Gornik, 2007: 68).

\section{References}

Alexander, R. 2008. Pedagogy, culture and curriculum. In P. Murphy, J. Soler, \& K. Hall (Eds.). Pedagogy and practice: Culture and identities. Northallerton: The Open University: Milton Keynes. pp. 3-27.

Apple, M.W. 2011. Global crises, social justice, and teacher education. Journal of Teacher Education, 62(2), 222-234. http://dx.doi.org/10.1177/0022487110385428

Arum, R. \& Roska, J. 2012. Academically adrift. Limited learning on college campuses. Chicago: Chicago Press.

Berlak, A. 2004. Confrontation and pedagogy: Cultural secrets and emotion in anti-oppressive pedagogies. In Democratic Dialogue in Education: Troubling Speech, Disturbing Silence. New York: Peter Lang. pp. 123-144. 
Bernstein, B. 1999. Official knowledge and pedagogic identities. In F. Christie (Ed.). Pedagogy and the shaping of consciousness. London: Continuum pp. 148.

Beyer, L. 2001. The value of critical perspectives in teacher education. Journal of Teacher Education, 52(3), 151-163 http://dx.doi.org/10.1177/0022487101052002006

Christensen, L.M. 2000. Critical literacy: Teaching reading, writing, and outrage. Trends and Issues in Secondary English, 11(2), 234-245.

Cohen, W. 1999. Learning trees and rules with set valued features. In 14th Conference of the American Association of Artificial Intelligence, AAAI.

Cullen, R. \& Hill, R.R. 2013. Curriculum designed for an equitable pedagogy. Education Sciences, 3, 17-29. http://dx.doi.org/10.3390/educsci3010017

Darling-Hammond, L. \& Ducommun, C. 2012. Recognizing and developing effective teaching: What policy makers should know and do. New York: Teachers College Press.

De Leon, A. \& Ross, 2010. Critical theories, radical pedagogies, and social education. New Perspectives for Social Studies Education. Boston: Sense Publishers.

Department of Higher Education and Training (DHET). 2015. Minimum requirements for teacher education qualifications. Government Gazette, 38487. Pretoria: Government Printers.

Dewey, J. 1938. Experience and education. New York: Collier.

Freire, P. 1970. Pedagogy of the oppressed. New York: Continuum.

Freire, P. 2005. Pedagogy of the oppressed, $30^{\text {th }}$ anniversary edition. New York: The Continuum International Publishing Group Inc.

Furumoto, W. 2003. Reconnecting education to social justice. Amerasia Journal, 29(2), 1-7. http://dx.doi.org/10.17953/amer.29.2.d3625q467wn4k3u0

Giroux, H. A. 1988. Teachers as intellectuals. New York: Bergin and Garvey.

Giroux, H. A. 2009. Youth in a suspect society: Democracy or disposability? New York: Palgrave-Macmillan. http://dx.doi.org/10.1057/9780230100565

Hawkins, D. 1974. The informed vision: Essays on learning and human nature. New York: Agathon Press.

Held, D. 1980. Introduction to critical theory. London: Hutchinson and Co, Ltd.

Henderson, J.G. \& Gornik, R. 2007. Transformative curriculum enquiry, 3rd edition. New Jersey: Pearson.

Horkheimer, M. 1972. Bemerkungen zur Religion. Frankfurt: Fisher Verslag.

Kaufman, B. 1984. Philosophy, common sense, and action in educational administration. Victoria, Australia: Deakin University.

Korthagen. F. 2002. Reframing teacher education: The realistic model. Teachers and Teaching: Theory and Practice, 2(2), 161-190.

Landman, W.A., Kilian, C.J.G., Swanepoel, E.M. \& Bodenstein, H.C.A. 1982. An introductory reader in fundamental pedagogics for the students and the teacher. Cape Town: Juta. 
Meadows, D. 2002. Dancing with systems. Systems Thinking, 13, 2-6.

Moll, I, 2004. Curriculum responsiveness: The anatomy of a concept. In H. Griesel (Ed.). Curriculum responsiveness case studies in higher education. Pretoria: South African Universities' Vice-Chancellors' Association (SAUVCA).

Morrow, W.E. 2007. Learning to teach in South Africa. Pretoria: HSRC Press.

Popkewitz, T. 1984. Paradigm and ideology in educational research. New York: The Falmer Press.

Reeves, C. \& Robinson, M. 2014. Assumptions underpinning the conceptualization of professional learning in teacher education. South African Journal of Higher Education, 28(1), 236-253.

Rodgers, C. 2002. Seeing student learning: Teacher change and the role of reflection. Harvard Education Review, 72(2), 230-253. http://dx.doi.org/10.17763/haer.72.2.5631743606m15751

Schmidt, A. A. 2008. Development and validation of the Toxic Leadership Scale. Available at < http://drum.lib.umd.edu/bitstream/1903/8176/1/umi-umd-5358.pdf> [Accessed 19 February 2016].

Slonimsky, L. \& Shalem, Y. 2006. Pedagogic responsiveness for academic depth. Journal of Education, 40, 35-58.

The Hechinger Report. 2008. Understanding and reporting on academic rigor. The Hechinger Institute on Education and Media. Teacher College. Collumbia University.

Tintiangco-Cubales, A., Kiang, P.N. \& Museus, S.D. 2010. Praxis and power in the intersections of education. AAPI Nexus, 8(1), 5-8.

Zinn, D., Geduld, D., Delport, A. \& Jordaan, C. 2014. 'Learning walks': Dialogic spaces for integrating theory and practice in a renewed B.Ed. foundation phase programme. South African Journal of Childhood Education, 3(4), 103-121. 